\title{
COVID-19 Vaccination in Patients with Inflammatory Bowel Disease: A Survey from China
}

\author{
Cong Dai ${ }^{1} \mathbb{C} \cdot$ Min Jiang $^{1} \cdot$ Yu-hong Huang ${ }^{1}$
}

Received: 18 May 2021 / Accepted: 7 July 2021 / Published online: 19 August 2021

(c) The Author(s), under exclusive licence to Springer Science+Business Media, LLC, part of Springer Nature 2021

\begin{tabular}{|c|c|}
\hline \multicolumn{2}{|c|}{ Abbreviations } \\
\hline COVID 19 & coronavirus disease 19 \\
\hline $\mathrm{ECCO}$ & European Crohn's and Colitis \\
\hline & Organisation \\
\hline IBD & inflammatory bowel disease \\
\hline mRNA & messenger ribonucleic acid \\
\hline SARS-CoV-2 & $\begin{array}{l}\text { severe acute respiratory syndrome corona- } \\
\text { virus } 2\end{array}$ \\
\hline
\end{tabular}

To the Editors,

We read with interest the article by Bénédicte Caron et al., who performed a survey to assess the acceptance of COVID19 vaccination among patients with inflammatory bowel disease (IBD) [1]. They found that half of the patients with IBD wished to be vaccinated against SARS-CoV-2. But we reached different conclusions via a questionnaire including patient characteristics and the acceptance of COVID-19 vaccination among patients with IBD at our IBD center.

A total of 218 patients (65 patients with Crohn's disease and 153 patients with ulcerative colitis) participated in the questionnaire, including 85 (38.99\%) women and $133(61.01 \%)$ men (Table 1$)$. The median age of patients was 34.2 years; $23.85 \%$ were current smokers, $65.6 \%$ were nonsmokers, and $10.55 \%$ had given up smoking. One hundred eighty-four $(84.4 \%)$ patients reported that their disease was in a clinical remission period based on clinical symptoms, and 34 (15.6\%) patients had symptoms including fever, abdominal pain, diarrhea, hematochezia, and vomiting. These patients were treated with 5-aminosalicylic acid (5-ASA; $51.83 \%)$, corticosteroids $(4.13 \%)$,

Cong Dai

congdai2006@sohu.com

1 Department of Gastroenterology, First Affiliated Hospital, China Medical University, No. 92 of Beier Road, Heping District, Shenyang City 110001, Liaoning Province, China immunosuppressants (5.04\%), biologic therapy $(36.24 \%)$, and other treatments $(2.75 \%)$.

A minority of patients $(38.53 \%)$ received a COVID-19 vaccine, and $61.47 \%$ did not receive a COVID-19 vaccine. There was no significant difference with regard to gender, disease type, course of disease, or disease activity between these two groups. But the proportion of patients aged $>40$ and smokers was higher in the vaccinated group than in the non-vaccinated group. The proportion of patients treated with 5-ASA was higher in the vaccinated group than in the non-vaccinated group.

The main reasons among patients who received the COVID-19 vaccine were as follows: $89.29 \%$ of patients believed that the vaccine protects against SARS-CoV-2 infection, $70.24 \%$ of patients desired to return to normal life, and $22.62 \%$ of patients believed in herd immunity. Twentythree patients $(27.38 \%)$ believed in social responsibility, and 67 patients $(79.76 \%)$ believed that COVID-19 vaccines had a promising safety profile. The main reasons among patients who did not receive the COVID-19 vaccine were as follows: $88.06 \%$ of patients were afraid of the risk of adverse reaction to vaccine, and $33.58 \%$ of patients believed that the vaccine was being developed too quickly. Twenty-one patients $(15.67 \%)$ were not confident in the vaccine research and development process, 37 patients $(27.61 \%)$ had a personal history of allergic reactions, 18 patients $(13.43 \%)$ believed that the vaccine would not work, 12 patients $(8.96 \%)$ were disappointed that they did not have a choice between vaccines, and eight patients $(5.97 \%)$ were not confident in the pharmaceutical industry. In addition, $51.49 \%$ of patients believed that the long-term safety of vaccines was unknown, $63.43 \%$ of patients believed that they had a low risk of becoming infected with SARS-CoV-2, 38.06\% of patients were not confident in how long protection would last after vaccination, and $70.9 \%$ of patients did not receive COVID19 vaccine because their doctor had not recommended a COVID-19 vaccine to them.

In conclusion, we found that the majority of patients with IBD in China did not receive a COVID-19 vaccine. The 
Table 1 Demographic and clinical features of IBD patients

\begin{tabular}{|c|c|c|}
\hline & Vaccinated & Not vaccinated \\
\hline Patients & $84(38.53 \%)$ & $134(61.47 \%)$ \\
\hline \multicolumn{3}{|l|}{ Gender } \\
\hline Male & $52(61.90 \%)$ & $81(60.45 \%)$ \\
\hline Female & $32(39.10 \%)$ & $53(39.55 \%)$ \\
\hline \multicolumn{3}{|l|}{ Disease } \\
\hline $\mathrm{CD}$ & $23(27.38 \%)$ & $42(31.34 \%)$ \\
\hline $\mathrm{UC}$ & $61(72.62 \%)$ & $92(68.66 \%)$ \\
\hline \multicolumn{3}{|l|}{ Age } \\
\hline$\leq 16$ & $8(9.52 \%)$ & $17(12.69 \%)$ \\
\hline $16 \sim 40(>16, \leq 40)$ & $49(58.33 \%)$ & $97(72.39 \%)$ \\
\hline $40 \sim 65(>40, \leq 65)$ & $21(25 \%)$ & $18(13.43 \%)$ \\
\hline$>65$ & $6(7.14 \%)$ & $2(1.49 \%)$ \\
\hline \multicolumn{3}{|l|}{ Smoking status } \\
\hline Never smoked & $47(55.95 \%)$ & $96(71.64 \%)$ \\
\hline Smoking & $29(34.52 \%)$ & $23(17.16 \%)$ \\
\hline Given up smoking & $8(9.52 \%)$ & $15(11.19 \%)$ \\
\hline \multicolumn{3}{|l|}{ Course of disease } \\
\hline$\leq 2$ years & $26(30.95 \%)$ & $48(35.82 \%)$ \\
\hline $2 \sim 5$ years ( $>2$ years, $\leq 5$ years) & $36(42.86 \%)$ & $53(39.55 \%)$ \\
\hline $5 \sim 10$ years $(>5$ years, $\leq 10$ years $)$ & $19(22.62 \%)$ & $22(16.42 \%)$ \\
\hline$>10$ years & $3(3.57 \%)$ & $11(8.21 \%)$ \\
\hline \multicolumn{3}{|l|}{ Therapy } \\
\hline 5-ASA & $62(73.81 \%)$ & $51(38.06 \%)$ \\
\hline Corticosteroid & $3(3.57 \%)$ & $6(4.48 \%)$ \\
\hline Immunosuppressant & $2(2.38 \%)$ & $9(6.72 \%)$ \\
\hline Biologic therapy & $16(19.05 \%)$ & $63(47.01 \%)$ \\
\hline Other treatment & $1(1.19 \%)$ & $5(3.73 \%)$ \\
\hline \multicolumn{3}{|l|}{ Disease activity } \\
\hline Remission period & $65(77.38 \%)$ & $119(88.81 \%)$ \\
\hline Relapse period & $19(22.62 \%)$ & $15(11.19 \%)$ \\
\hline \multicolumn{3}{|l|}{ Main reasons for intending to get COVID-19 vaccine } \\
\hline Protection against SARS-CoV-2 infection & $75(89.29 \%)$ & - \\
\hline Promising safety profile & $67(79.76 \%)$ & - \\
\hline Social responsibility & $23(27.38 \%)$ & - \\
\hline Herd immunity & $19(22.62 \%)$ & - \\
\hline Desire to return to normal life & $59(70.24 \%)$ & - \\
\hline \multicolumn{3}{|l|}{ Main reasons for not intending to get COVID-19 vaccine } \\
\hline Risk of adverse reaction to vaccine & - & $118(88.06 \%)$ \\
\hline Personal history of allergic reactions & - & $37(27.61 \%)$ \\
\hline The vaccine will not work & - & $18(13.43 \%)$ \\
\hline Low risk of being infected with SARS-CoV-2 & - & $85(63.43 \%)$ \\
\hline Unknown long-term safety & - & $69(51.49 \%)$ \\
\hline Concern that the vaccine is being developed too quickly & - & $45(33.58 \%)$ \\
\hline Not confident in vaccine $R \& D$ process & - & $21(15.67 \%)$ \\
\hline No information about how long protection lasts after vaccination & - & $51(38.06 \%)$ \\
\hline No choice between vaccines & - & $12(8.96 \%)$ \\
\hline Don't trust the pharmaceutical industry & - & $8(5.97 \%)$ \\
\hline Doctor has not recommended a COVID-19 vaccine to me & - & $95(70.90 \%)$ \\
\hline
\end{tabular}

$C D$ Crohn's disease, $U C$ ulcerative colitis, $R \& D$ research and development 
main reasons include the risk of adverse reaction to vaccine, low risk of being infected with SARS-CoV-2, and no recommendations regarding a COVID-19 vaccine by a doctor.

\section{Reply}

We thank Dai and colleagues for their letter. In their cohort, the majority of patients with inflammatory bowel disease (IBD) in China (61.47\%) did not receive a coronavirus disease 19 (COVID-19) vaccine. The main reasons include the risk of adverse reaction to vaccine, low risk of infection with severe acute respiratory syndrome coronavirus 2 (SARSCoV-2), and no recommendation regarding a COVID-19 vaccine by a doctor. It is not known whether health care professionals received recommendations regarding COVID-19 vaccination. In our study, half of patients with IBD wished to be vaccinated against SARS-CoV-2, and this rate was similar to that reported in the French general population [1]. In Italy, a survey measured the acceptance of anti-SARS-CoV-2 vaccination in an IBD population, and the proportion of patients willing to be vaccinated against SARS-CoV-2 was 53.6\%, which is similar to our cohort [2]. The high rate of vaccine acceptance in Europe could be explained, at least in part, by the recommendations of the European Crohn's and Colitis Organisation (ECCO) task force to use the mRNA (messenger ribonucleic acid) vaccine to vaccinate IBD patients, published in February 2021 [3]. In addition, the difference in adherence to COVID-19 vaccination between Europe and China might be partly attributable to cultural and socioeconomic discrepancies. When we performed the survey in the French IBD population, the third wave of the COVID-19 pandemic in France had just begun. Perhaps the population in China did not perceive the need for vaccination due to the low incidence of COVID-19 when they performed their survey. The rate of COVID-19 vaccination intent in the general population in China is unknown. To improve COVID19 vaccination coverage and raise the levels of population immunity, in particular in the IBD population, national and international recommendations, and culturally sensitive and appropriate communication to encourage their uptake, are needed.
Bénédicte Caron, Elise Neuville, Laurent Peyrin-Biroulet. Department of Gastroenterology and Inserm NGERE U1256, Nancy University Hospital,

University of Lorraine, 54500 Vandoeuvre-lès-Nancy, France.

Corresponding author:

Prof. Laurent Peyrin-Biroulet, MD, PhD.

Inserm NGERE U1256 and Department of Gastroenterology.

Nancy University Hospital, University of Lorraine.

1 Allée du Morvan, 54511 Vandoeuvre-lès-Nancy, France

E-mail: peyrinbiroulet@gmail.com.

Authors' contribution $\mathrm{CD}$ wrote the paper. $\mathrm{CD}$ and $\mathrm{YH}$ conceived the idea for the paper. All authors reviewed and approved the final draft of the paper.

Funding None.

\section{Declarations}

Conflict of interest The authors declare that they have no competing interests.

\section{References}

1. Caron B, Neuville E, Peyrin-Biroulet L. Inflammatory bowel disease and COVID-19 vaccination: a patients' survey. Dig Dis Sci. 2021. https://doi.org/10.1007/s10620-021-07040-z.

2. Crispino F, Brinch D, Carrozza L, Cappello M. Acceptance of SARS-CoV-2 vaccination among a cohort of IBD patients from Southern Italy: a cross-sectional survey. Inflamm Bowel Dis. 2021. https://doi.org/10.1093/ibd/izab133.

3. ECCO Information on COVID-19. Accessed June 16, 2021. https://www.ecco-ibd.eu/publications/covid-19.html

Publisher's Note Springer Nature remains neutral with regard to jurisdictional claims in published maps and institutional affiliations. 